\title{
COLONIAL VARIANTS OF PROTEUS SPECIES: THEIR GROWTH REQUIREMENTS, BIOCHEMICAL CHARACTERS AND RESISTANCE TO ANTIBACTERIAL AGENTS
}

\author{
Ruth M. M. Klemperer, D. A. Al-Dujaili* and \\ M. R. W. BROWN \\ Microbiology Research Group, Department of Pharmacy, University of Aston, Birming- \\ ham B4 $7 E T$
}

\begin{abstract}
Summary. Stable small-colony variants of Proteus species were isolated and characterised. They differed from typical organisms in their morphology, biochemical properties and drug resistance. They were found most frequently in culture media of low osmolarity. Their growth rate was depressed at high concentrations of salts, which had only a small effect on typical organisms. This may be important in the routine isolation of Proteus spp. and in testing of disinfectants.
\end{abstract}

\section{INTRODUCTION}

Colonial variation associated with changes in somatic antigens was first observed in Proteus species by Felix (1922) and analysed by Belyavin (1951) who distinguished three colonial forms on MacConkey agar. Typical freshly isolated organisms (phase A) gave rise to either phase-B or phase-C variants, and these changes were reversible. Phase- $C$ variants were highly motile filamentous forms, which were antigenically indistinguishable from phase $\mathrm{A}$. Phase-B variants, however, had largely lost their type-specific surface antigens, and their virulence for mice was significantly less than that of phase A.

Small-colony variants, which are sensitive to high concentrations of salts, tend to emerge when Proteus species are grown in simple salts media (Al-Dujaili, Klemperer and Brown, 1977). This paper describes their properties in detail.

\section{MATERIALS AND METHODS}

Bacterial strains. The strains used were Proteus mirabilis NCTC nos. 60, 5887, 7827 and 8309, National Collection of Industrial Bacteria (NCIB) no. 2100, and a polymyxin-sensitive clinical isolate from Dr T. D. M. Martin, Royal Berkshire Hospital, Reading, which we designated strain RBH; Proteus vulgaris NCIB nos. 8259 and 8261; and Proteus morgani NCIB no. 10466. Cultures were stored on Nutrient Agar (Oxoid) slopes at $4^{\circ} \mathrm{C}$ and subcultured monthly.

Culture media. The commercial culture media used were: Nutrient Broth (Oxoid CM1) (NuB); Peptone Water (Oxoid L37) (PW); Nutrient Agar (Oxoid CM3) (ONA); and Nutrient

Received 10 Mar. 1980; revised version accepted 27 Jun. 1981.

* Present address: Pharmacy College, Baghdad University, Iraq. 
Agar (Gibco Dri-Form) (GNA). For media to prevent swarming, Lab M Agar MC2 (London Analytical and Bacteriological Media Ltd, 50 Mark Lane, London EC3R 7QT) was added to ONA or GNA to give a final concentration of agar of $3.8 \%$ (ONAA and GNAA respectively). Other media used were Bacto Cysteine-Lactose-Electrolyte-Deficient agar (Difco) (CLED), MacConkey Agar No. 2 (Oxoid), and Diagnostic Sensitivity Test Agar (Oxoid) (DST).

Chemically defined media (CDM) A and B were prepared with the composition shown in table I. All chemicals were Analar grade from BDH Chemicals Ltd, Fancy Road, Poole, Dorset BH12 4NN. Glucose and nicotinic acid were filtered and the others were autoclaved. Modifications of the composition of CDM are noted in the tables.

Media for biochemical tests were from Oxoid Ltd, except Urea Agar (Gibco Diagnostics) and Sulphide-Indole-Motility Medium (Difco) (SIM). Multodisks (Oxoid) were used for testing sensitivity to antibiotics. Polymyxin was kindly donated by $\mathrm{Dr}$ J. Gurney, Wellcome Research Laboratories, Beckenham, Kent, cetrimide was from BDH Chemicals Ltd, chlorhexidine gluconate (Hibitane) from ICI Ltd, Macclesfield, Cheshire and phenol from Fisons Ltd, Loughborough, Leics.

Selection of organisms forming typical large colonies $(L c)$ was by terminal dilution in $\mathrm{NuB}$ (Meynell and Meynell, 1970) and the overnight cultures were stored at $-196^{\circ} \mathrm{C}$. Lc of $P$. mirabilis strain $\mathrm{RBH}$ were also selected by subculturing polymyxin-sensitive colonies from ONAA plates, as demonstrated by replica plating on to ONAA containing polymyxin ( 250 $\mathrm{u} \mathrm{ml}^{-1}$ ) (Meynell and Meynell, 1970).

Isolation of variants forming small colonies (Sc). Cultures were grown overnight in CDM B at $37^{\circ} \mathrm{C}$, plated on ONAA and incubated for $24-48 \mathrm{~h}$. Small colonies were inoculated on to ONA slopes which were incubated for $48 \mathrm{~h}$ and stored at $4^{\circ} \mathrm{C}$.

Biochemical characteristics. Tests had to be chosen to permit adequate growth of Sc. Except for phenylalanine deamination (method of Snell and Davey, 1971) and $\mathrm{H}_{2} \mathrm{~S}$ formation, assessed from the appearance of SIM medium, the methods of Cowan (1974) were used. When alternative methods are described the following were used: oxidase, catalase and VP, method no. 1; citrate and gelatin, method no. 2; indole, method no. 3; and urease, methods nos. 1 and 5. Phenylalanine deamination by strain RBH was also tested by method no. 2, but Sc of other strains would not grow on this medium.

Growth studies. Inocula were prepared in CDM A containing $0.1 \mathrm{M} \mathrm{KCl}$ for $\mathrm{Lc}$ and $5 \times 10^{-5} \mathrm{M} \mathrm{KCl}$ for Sc. All batch cultures were in $25-\mathrm{ml}$ volumes in $100-\mathrm{ml}$ conical flasks and were shaken at $37^{\circ} \mathrm{C}$. Growth was monitored by absorbance readings at $420 \mathrm{~nm}$. The number of colony-forming units was determined with samples serially diluted in $\mathrm{NuB}$, surface spread on ONAA or GNAA (five replicates) and incubated for $36 \mathrm{~h}$. Results for Sc probably underestimated the actual number of viable cells by at least $50 \%$ because of chain formation.

Drug sensitivity. For testing sensitivity to antibiotics, overnight cultures in NuB were diluted 100-fold ( $\mathrm{Lc}$ ), 50-fold (Sc, to give the same absorbance as Lc) and plated on GNA or DST. Plates were flooded with culture and excess fluid was removed. Multodisks were applied and the cultures were incubated at $37^{\circ} \mathrm{C}$ for $18 \mathrm{~h}$. Tests were done in duplicate and repeated at least once. Inhibition of growth was recorded if a zone of no growth clearly extended more than

TABLE I

Composition of chemically defined culture media $A$ and $B$

\begin{tabular}{l|rr}
\hline \multicolumn{1}{c|}{ Chemical } & \multicolumn{2}{c}{ Molar concentration in } \\
\cline { 2 - 2 } CDM A & CDM B \\
\hline Glucose & $2 \times 10^{-3}$ & $4 \times 10^{-2}$ \\
Ammonium sulphate & $5 \times 10^{-5}$ & $2 \times 10^{-4}$ \\
Magnesium sulphate & $10^{-4}$ & $2 \times 10^{-4}$ \\
Potassium chloride & $5 \times 10^{-5}$ & $5 \times 10^{-5}$ \\
Sodium chloride & $5 \times 10^{-5}$ & $5 \times 10^{-5}$ \\
Nicotinic acid & $6 \times 10^{-5}$ & $6 \times 10^{-5}$ \\
Ammonium phosphate buffer $p \mathrm{H} \mathrm{7.2}$ & $10^{-1}$ & $10^{-1}$ \\
\hline
\end{tabular}

$\mathrm{CDM}=$ chemically defined medium (see Materials and methods). 
$2 \mathrm{~mm}$ from the edge of the disc (manufacturer's recommendation). For determination of sensitivity to membrane-active agents, a cell suspension in the stationary phase (absorbance at $\mathrm{A}_{420}, 0 \cdot 2$ ) was prepared by washing log-phase cells twice in CDM A, resuspending them in glucose-free CDM A and incubating them for $30 \mathrm{~min}$ at $37^{\circ} \mathrm{C}$. The number of colony-forming units in the culture was estimated, the drug was added, and the culture incubated at $37^{\circ} \mathrm{C}$. Samples were taken at intervals and the drug action was stopped by tenfold dilution in NuB in the experiments with phenol (Russell, Ahonkhai and Rogers, 1979), in lecithin-glycerol broth for polymyxin, or in lecithin-tween broth for cetrimide and for chlorhexidine (Kohn, Gershenfeld and Barr, 1963). Survival was calculated from the number of colony-forming units after drug treatment, expressed as a percentage of the initial count.

\section{RESULTS}

\section{Occurrence of Sc variants}

Sc variants were occasionally isolated from Proteus mirabilis strains $\mathrm{RBH}$ and NCTC5887 during several years in investigations on sensitivity to disinfectants. To find out whether this was a general phenomenon, more strains were tested, and Sc were isolated from all, except $P$. vulgaris strain NCIB8259. This last strain was cultured only a few times. As a further check, a second sample of each NCTC and NCIB strain of P. mirabilis and P. morgani was obtained from the culture collections and Sc were again isolated.

\section{Colonial characteristics and bacterial morphology}

All the strains of Proteus, except NCIB10466, swarmed on nutrient agar (ONA or GNA). When swarming was prevented by excess agar (ONAA or GNAA), they formed typical Lc, diameter 2-3 mm, which were low, irregular in outline, matt and translucent. Sc variants were easily distinguished after 48 $\mathrm{h}$ on ONAA (fig. 1). The colonies were usually $0.5 \mathrm{~mm}$ or less in diameter,

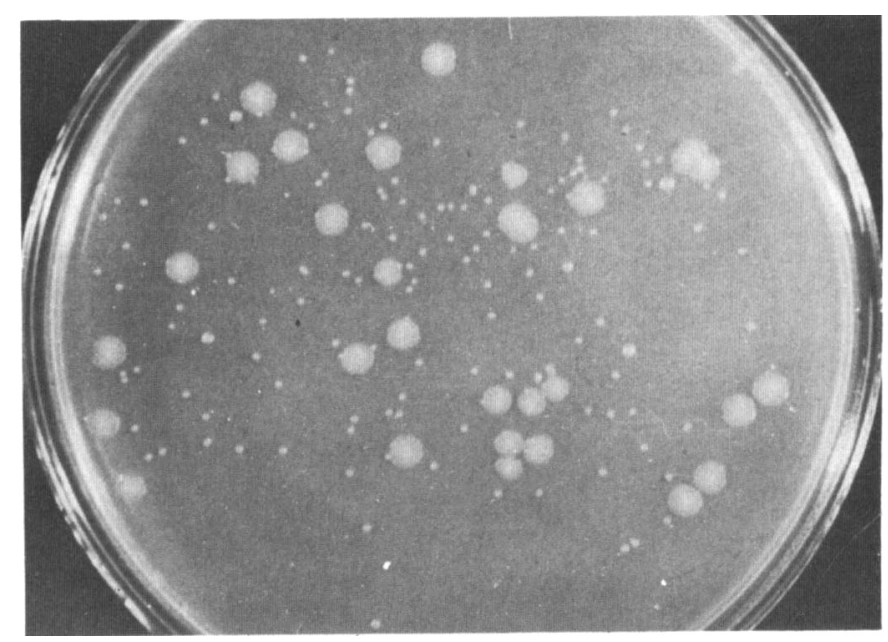

FIG. 1.-P. mirabilis strain NCTC5887 after 48-h incubation at $37^{\circ}$ on ONAA (see Materials and methods), showing large-colony and small-colony variants. $\times 2$. 


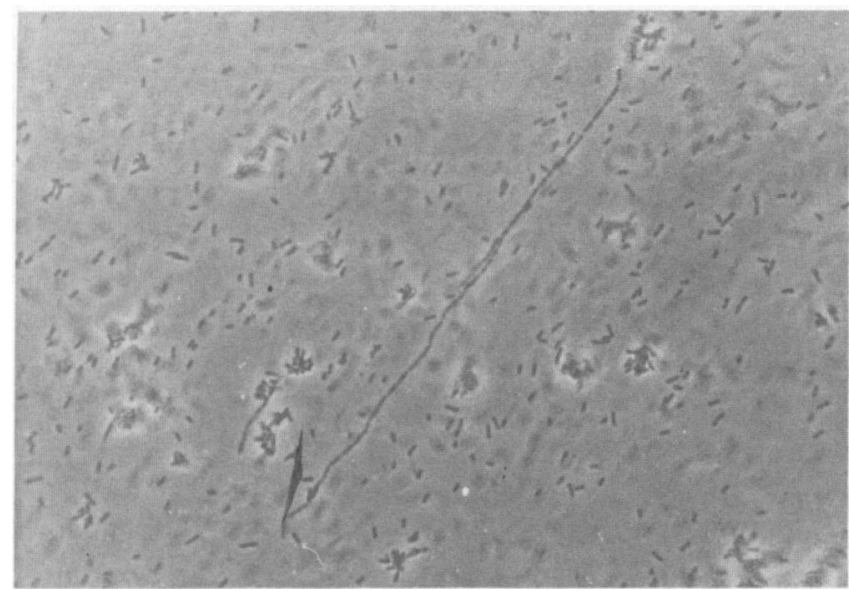

FIG. 2.-Proteus mirabilis strain NCTC5887 small-colony variant. Phase contrast. $\times 730$.

circular, entire, domed, smooth and opaque. On ONA their appearance was similar after $24 \mathrm{~h}$ at $37^{\circ} \mathrm{C}$.

When 3-h or 24-h cultures in NuB, PW or any CDM were examined by phase-contrast microscopy, Lc and Sc appeared as short rods. However, Sc were often arranged in pairs, with some short chains of four or five cells, and occasionally longer chains of up to 50 cells (fig. 2). Organisms from all Lc, but not from Sc, were motile in SIM medium, or in hanging drops from cultures in $\mathrm{NuB}$ or $\mathrm{CDM}$ at $37^{\circ} \mathrm{C}$. Sc from $P$. mirabilis strains RBH, NCTC5887 and NCTC8309 were investigated further in a variety of conditions. In PW or NuB containing 0.02M glucose NCTC5887 Sc and NCTC8309 Sc were motile, but RBH Sc were not.

\section{Stability of variant forms}

Typical Lc were not stable and gave rise to varying numbers of Sc, the frequency of the detection of Sc apparently being determined by the relative ability of $\mathrm{Lc}$ and $\mathrm{Sc}$ to grow in the various culture media. Lc clones of $P$. mirabilis strains RBH and NCTC5887, selected by terminal dilution, gave rise to $\mathrm{Sc}$ on subculture in appropriate media. Lc cultures of strain RBH, derived from single Lc colonies shown by replica plating to be sensitive to polymyxin $\left(250 \mathrm{u} \mathrm{ml}^{-1}\right)$, also yielded Sc on serial subculture.

In contrast, Sc cultures were always stable. On no occasion was a Lc isolated from a Sc culture. P. mirabilis strains RBH (Sc) and NCTC5887 (Sc) were subcultured serially 20 times on moist plates of GNA and ONA which would have permitted any Lc to swarm out from a colony, but Lc were not found. The same result was obtained with MacConkey agar.

The effect of $\mathrm{NaCl}$ and $\mathrm{KCl}$ on the occurrence of Sc variants

Sc were first identified on ONAA, which contains $0.5 \%$ added $\mathrm{NaCl}$ (manufacturer's formula). On GNAA and CLED, which do not have added 
TABLE II

The occurrence of small-colony variants of Proteus mirabilis strain NCTC5887 in culture media with different concentrations of $\mathrm{NaCl}$ or $\mathrm{KCl}$ : results of a typical experiment

\begin{tabular}{lcc|c}
\hline \multirow{2}{*}{ Medium } & \multicolumn{2}{c|}{ Molarity of } & \multicolumn{2}{c}{$\begin{array}{c}\text { Percentage of } \\
\text { Sc variants }\end{array}$} \\
\cline { 2 - 4 } & $\mathrm{NaCl}$ & $\mathrm{KCl}$ & 0 \\
$\mathrm{NuB}$ & $>0.09^{*}$ & Not known & 05 \\
$\mathrm{CDM} \mathrm{A}$ & $5 \times 10^{-5}$ & $5 \times 10^{-5}$ & 95 \\
& $5 \times 10^{-5}$ & $0 \cdot 1$ & 92 \\
& $5 \times 10^{-5}$ & $0 \cdot 2$ & 0 \\
& $0 \cdot 1$ & $5 \times 10^{-5}$ & 50 \\
& 0.15 & $5 \times 10^{-5}$ & 2 \\
& 0.2 & $5 \times 10^{-5}$ & 0 \\
\hline
\end{tabular}

$\mathrm{Sc}=$ small-colony $; \mathrm{NuB}=$ nutrient broth $; \mathrm{CDM}=$ chemically defined medium (see Materials and methods). $* 0.5 \%$ added $\mathrm{NaCl}$, manufacturer's formula.

$\mathrm{NaCl}$, Sc colonies were larger than on ONAA and more difficult to distinguish from Lc.

Sc were rarely detected by direct plating from $\mathrm{NuB}$; cultures in CDM containing $10^{-1} \mathrm{M}$ ammonium phosphate but all other salts in very low concentrations $\left(10^{-4} \mathrm{M}\right.$ or less), yielded variable numbers. When the concentration of $\mathrm{KCl}$ or $\mathrm{NaCl}$ was increased to a level comparable with that of $\mathrm{NaCl}$ in $\mathrm{NuB}$, the number of Sc detected was greatly reduced. Table II shows the results of a typical experiment.

The proportion of Sc at high concentrations of salts varied in different experiments (compare tables II and III), but the general pattern of inhibition at high concentrations was maintained. Similar results were obtained with all strains yielding Sc, except $P$. vulgaris strain NCIB8261, which was not tested in this way. Serial subculture in CDM of $P$. mirabilis strains NCTC5887 and RBH (table III) suggested that even when Sc were not detectable at high salt concentrations they might still be able to survive and subsequently to become predominant at low salt concentrations. In such experiments, however, it is not possible to exclude the possibility that $\mathrm{Sc}$ are newly formed.

TABLE III

The effect of $\mathrm{KCl}$ on the detection of small-colony variants of P. mirabilis strain NCTC5887 after serial subculture in $C D M A$

\begin{tabular}{cc|c}
\hline $\begin{array}{c}\text { Culture* } \\
\text { no. }\end{array}$ & $\begin{array}{c}\text { Molarity } \\
\text { of KCl }\end{array}$ & $\begin{array}{c}\text { Percentage of } \\
\text { Sc variants }\end{array}$ \\
\hline 1 & $0 \cdot 2$ & 10 \\
2 & $0 \cdot 2$ & 41 \\
$2+$ & $0 \cdot 3$ & 0 \\
3 & $5 \times 10^{-5}$ & $99 \cdot 7$ \\
3 & $0 \cdot 1$ & 1 \\
3 & $0 \cdot 2$ & 0 \\
3 & $0 \cdot 3$ & 0 \\
\hline
\end{tabular}

Abbreviations as in table II.

* Typical experiment; similar results with $P$. mirabilis strain $\mathrm{RBH}$.

+ Used to inoculate cultures no. 3 . 
TABLE IV

The doubling time of large-colony and small-colony variants of $P$. mirabilis strains $R B H$ and NCTC5887 growing in CDM A with different concentrations of $\mathrm{KCl}$

\begin{tabular}{|c|c|c|c|c|c|c|c|}
\hline \multicolumn{2}{|c|}{ P. mirabilis } & \multicolumn{6}{|c|}{ Doubling time* at $\mathrm{KCl}$ molarity of } \\
\hline Strain & Colony type & $5 \times 10^{-5}$ & $0 \cdot 1$ & 0.15 & $0 \cdot 2$ & 0.3 & 0.4 \\
\hline $\mathrm{RBH}$ & $\begin{array}{l}\text { Lc } \\
\text { Sc }\end{array}$ & $\begin{array}{l}69 \\
75\end{array}$ & $\begin{array}{r}80 \\
102\end{array}$ & $\begin{array}{r}91 \\
148\end{array}$ & $\begin{array}{l}111 \\
206\end{array}$ & & 9 \\
\hline NCTC 5887 & $\begin{array}{l}\text { Lc } \\
\text { Sc }\end{array}$ & $\begin{array}{l}71 \\
76\end{array}$ & $\begin{array}{r}81 \\
102\end{array}$ & $\begin{array}{r}82 \\
135\end{array}$ & $\begin{array}{r}96 \\
259\end{array}$ & $\ddagger$ & $\begin{array}{c}85 \\
\S\end{array}$ \\
\hline
\end{tabular}

$\mathrm{Lc}=$ large colony; $\mathrm{Sc}=$ small colony

* Mean of 2-6 experiments, except with $0 \cdot 3$ and $0.4 \mathrm{M} \mathrm{KCl}$.

$\dagger$ No growth at $7 \mathrm{~h}$.

†ne doubling in $18 \mathrm{~h}$.

$\S$ One doubling in $21 \mathrm{~h}$.

The failure of Sc to appear at high salt concentrations appears to be due to an effect on the rate of growth. High concentrations of $\mathrm{KCl}$ have a greater adverse effect on Sc than on Lc (table IV). This may partly be due to a lower requirement for $\mathrm{KCl}$ by Sc. At limiting concentrations, Sc formed suspensions about twice as dense as Lc (fig. 3).

Because $\mathrm{Sc}$ were inhibited by high concentrations of either $\mathrm{NaCl}$ or $\mathrm{KCl}$, it seemed possible that the inhibition was osmotic. Table V shows that $0.66 \mathrm{M}$ sucrose, which has the same osmotic pressure as $0 \cdot 4 \mathrm{M} \mathrm{NaCl}$, markedly inhibited the growth of $P$. mirabilis strain RBH Sc.

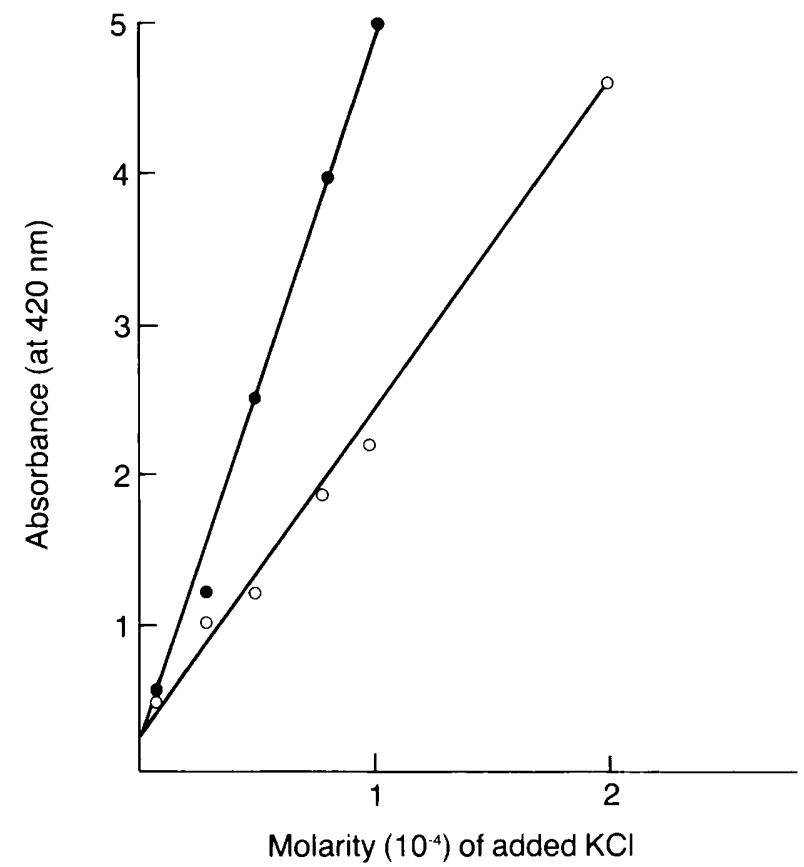

FIG. 3.-Absorbance at end of exponential growth in chemically defined medium $\mathrm{B}$ of large-colony and small-colony variants of $P$. mirabilis strain $\mathrm{RBH}$ as a function of $\mathrm{KCl}$ concentration. $\mathrm{O}-\mathrm{O}=$ largecolony, $\longrightarrow=$ small-colony variant. 
TABLE V

The optical density $\left(A_{420}\right)$ of large-colony and small-colony variants of $P$. mirabilis strain $R B H$ after incubation for $23 \mathrm{~h}$ in CDM $A$ with and without added sucrose

\begin{tabular}{|c|c|c|}
\hline \multirow[b]{2}{*}{ Colony type } & \multicolumn{2}{|c|}{$\begin{array}{l}\text { Optical density* } \\
\text { in medium with } \\
\text { sucrose molarity of }\end{array}$} \\
\hline & 0.66 & 0 \\
\hline $\begin{array}{l}\mathrm{Lc} \\
\mathrm{Sc}\end{array}$ & $\begin{array}{l}0.34 \\
0.065\end{array}$ & $\begin{array}{l}0.51 \\
0.47\end{array}$ \\
\hline
\end{tabular}

Abbreviations as in table IV.

* Mean of two experiments; initial density $=0.025$.

\section{Biochemical characters}

Lc and Sc variants of strains RBH, NCTC5887 and NCTC8309 were tested for biochemical activity. The results of tests in which differences between $\mathrm{Lc}$ and $\mathrm{Sc}$ variants were observed are given in table VI. The following tests gave the same results for Lc and Sc variants: deamination of phenylalanine; production of urease (by method 5 because Sc gave poor growth and a delayed positive reaction by method 1); activity against lactose, maltose, mannitol and sucrose; VP; production of indole; utilisation of citrate; liquefaction of gelatin; and growth on MacConkey agar. Lc and Sc variants of the other strains gave the same results in the tests listed in table VI, except that they were not tested for growth in $\mathrm{KCN}$ or production of $\mathrm{H}_{2} \mathrm{~S}$. In particular it may be noted that $\mathrm{Sc}$ failed to ferment glucose, and that there was a shift in the properties of haem compounds, Sc being catalase negative and oxidase positive and, except for strain RBH, Sc being sensitive to KCN. Growth of Sc on GNA was not found when plates were incubated anaerobically.

\section{Resistance to antibacterial agents}

Strains that were inhibited by aminoglycoside or $\beta$-lactam antibiotics in

TABLE VI

Biochemical characters of P. mirabilis strains RBH, NCTC5887 and NCTC8309 large-colony and small-colony variants

\begin{tabular}{l|cc}
\hline \multicolumn{1}{c|}{ Test } & \multicolumn{2}{|c}{ Reaction of } \\
\cline { 2 - 3 } & Lc & Sc \\
\hline $\begin{array}{l}\text { Glucose fermentation } \\
\text { Methyl-red reaction }\end{array}$ & Acid and gas & Acid \\
Oxidation/fermentation & + & - \\
Growth in KCN & Fermentation & Oxidation \\
Oxidase production & + & - (strain RBH +$)$ \\
Catalase production & + & + \\
$\mathrm{H}_{2}$ S production & + & - \\
\hline
\end{tabular}

$+=$ Positive; $-=$ negative. Other abbreviations as in table IV . 
TABLE VII

Sensitivity of Proteus spp., large-colony and small-colony variants, to antibiotics

\begin{tabular}{|c|c|c|c|c|c|c|c|c|c|c|c|c|c|c|c|}
\hline \multirow[b]{3}{*}{ Antibiotic } & \multirow{3}{*}{$\begin{array}{c}\text { Disc } \\
\text { content } \\
(\mu \mathrm{g})\end{array}$} & \multicolumn{14}{|c|}{ Sensitivity of strain } \\
\hline & & \multicolumn{2}{|c|}{$\mathrm{RBH}$} & \multicolumn{2}{|c|}{$\begin{array}{l}\text { NCTC } \\
60\end{array}$} & \multicolumn{2}{|c|}{$\begin{array}{l}\text { NCIB } \\
2100\end{array}$} & \multicolumn{2}{|c|}{$\begin{array}{c}\text { NCTC } \\
5887\end{array}$} & \multicolumn{2}{|c|}{$\begin{array}{c}\text { NCTC } \\
7827\end{array}$} & \multicolumn{2}{|c|}{$\begin{array}{l}\text { NCTC } \\
8309\end{array}$} & \multicolumn{2}{|c|}{$\begin{array}{l}\text { NCIB } \\
10466\end{array}$} \\
\hline & & $\mathrm{Lc}$ & $\mathrm{Sc}$ & Lc & $\mathrm{Sc}$ & $\mathrm{Lc}$ & $\mathrm{Sc}$ & Lc & $\mathrm{Sc}$ & $\mathrm{Lc}$ & $\mathrm{Sc}$ & $\mathrm{Lc}$ & $\mathrm{Sc}$ & $\mathrm{Lc}$ & Sc \\
\hline $\begin{array}{l}\text { Gentamicin } \\
\text { Kanamycin }\end{array}$ & $\left.\begin{array}{r}10 \\
5\end{array}\right\}$ & $S$ & $\mathrm{R}$ & $\mathrm{S}$ & $\mathrm{R}$ & $\mathrm{S}$ & $\mathrm{R}$ & $\mathrm{S}$ & $\mathrm{R}$ & $\mathrm{S}$ & $\mathrm{R}$ & $\mathrm{S}$ & $\mathrm{R}$ & $\mathrm{S}$ & $\mathrm{R}$ \\
\hline $\begin{array}{l}\text { Ampicillin } \\
\text { Ampicillin } \\
\text { Carbenicillin } \\
\text { Cloxacillin } \\
\text { Methicillin } \\
\text { Cephaloridine }\end{array}$ & $\begin{array}{r}2 \\
25 \\
100 \\
5 \\
10 \\
25\end{array}$ & $\begin{array}{l}\mathrm{S} \\
\mathrm{S} \\
\mathrm{S} \\
\mathrm{R} \\
\mathrm{R} \\
\mathrm{S}\end{array}$ & $\begin{array}{l}\mathrm{R} \\
\mathrm{S} \\
\mathrm{S} \\
\mathrm{R} \\
\mathrm{R} \\
\mathrm{R}\end{array}$ & $\begin{array}{l}S \\
S \\
S \\
R \\
S \dagger \\
S\end{array}$ & $\begin{array}{l}\mathrm{R} \\
\mathrm{R} \\
\mathrm{R} \\
\mathrm{R} \\
\mathrm{R} \\
\mathrm{R}\end{array}$ & $\begin{array}{l}S \\
S \\
S \\
S \dagger \\
S \\
S\end{array}$ & $\begin{array}{l}\mathrm{R} \\
\mathrm{R} \\
\mathrm{R} \\
\mathrm{R} \\
\mathrm{R} \\
\mathrm{R}\end{array}$ & $\begin{array}{l}S \\
S \\
S \\
R \\
R \\
S\end{array}$ & $\begin{array}{l}\mathrm{R} \\
\mathrm{R} \\
\mathrm{R} \\
\mathrm{R} \\
\mathrm{R} \\
\mathrm{R}\end{array}$ & $\begin{array}{l}S \\
S \\
S \\
R \\
R \\
S\end{array}$ & $\begin{array}{l}\mathrm{R} \\
\mathrm{R} \\
\mathrm{R} \\
\mathrm{R} \\
\mathrm{R} \\
\mathrm{R}\end{array}$ & $\begin{array}{l}\mathrm{S} \\
\mathrm{S} \\
\mathrm{S} \\
\mathrm{R} \\
\mathrm{R} \\
\mathrm{S}\end{array}$ & $\begin{array}{l}\mathrm{R} \\
\mathrm{R} \\
\mathrm{R} \\
\mathrm{R} \\
\mathrm{R} \\
\mathrm{R}\end{array}$ & $\begin{array}{l}\mathrm{R} \\
\mathrm{S}^{*} \\
\mathrm{~S} \\
\mathrm{R} \\
\mathrm{R} \\
\mathrm{R}\end{array}$ & $\begin{array}{l}\mathrm{R} \\
\mathrm{R} \\
\mathrm{R} \\
\mathrm{R} \\
\mathrm{R} \\
\mathrm{R}\end{array}$ \\
\hline Tetracycline & 50 & $\mathrm{R}$ & S & $\mathrm{S}^{*}$ & $\mathrm{~S}$ & $\mathrm{R}$ & $\mathrm{S}$ & $\mathrm{S}$ & $\mathrm{S}$ & $\mathrm{S}$ & $\mathrm{S}$ & $\mathrm{S}^{*}$ & $S$ & $\mathrm{~S}$ & $\mathrm{~S}$ \\
\hline
\end{tabular}

$\mathrm{S}=$ Zone $>2 \mathrm{~mm}$ from disc, $\mathrm{R}=$ zone $\leqslant 2 \mathrm{~mm}$ on Nutrient Agar (Gibco). Other abbreviations as in table IV.

* $\mathrm{R}$ on Diagnostic Sensitivy Test Agar (Oxoid).

+ Distinct zone of inhibition, but resistant colonies inside zone.

All cultures were sensitive to sulphamethoxazole ( $25 \mu \mathrm{g} \mathrm{disc})$ and sulphafurazole (500 $\mu \mathrm{g} \mathrm{disc})$.

this test formed Sc with increased resistance. The converse was found with tetracycline: resistant strains formed Sc that were more sensitive (table VII). In many cases in which the Lc and Sc variants showed a difference in sensitivity to an agent, the sensitive variant displayed a zone of inhibition considerably more than $2 \mathrm{~mm}$ from the disc edge, and in some as much as $18 \mathrm{~mm}$. GNA was used to give comparable densities of growth for Lc and Sc. DST, which is recommended for testing of antibiotic sensitivity by the disc method but which permitted denser growth of Lc than of Sc, gave different quantitative results in a few instances but the patterns of resistance remained the same. Strains NCTC5887 and RBH were also tested against membrane-active agents. Sc were more sensitive to phenol, but more resistant to chlorhexidine and

\section{TABLE VIII}

Sensitivity of P. mirabilis large-colony and small-colony variants to membrane-active agents

\begin{tabular}{|c|c|c|c|c|c|c|}
\hline \multirow[b]{3}{*}{ Agent } & \multirow{3}{*}{$\begin{array}{l}\text { Concentration } \\
\left(\mathrm{ml}^{-1}\right)\end{array}$} & \multirow{3}{*}{$\begin{array}{l}\text { Time } \\
(\min )\end{array}$} & \multicolumn{4}{|c|}{ Percentage survival* of } \\
\hline & & & \multicolumn{2}{|r|}{$\begin{array}{l}\text { strain } \\
\mathrm{RBH}\end{array}$} & \multicolumn{2}{|c|}{$\begin{array}{c}\text { strain } \\
\text { NCTC5887 }\end{array}$} \\
\hline & & & Lc & $\mathrm{Sc}$ & $\mathrm{Lc}$ & Sc \\
\hline None & & $\begin{array}{l}120 \\
180\end{array}$ & $\begin{array}{l}99 \\
95\end{array}$ & $\begin{array}{r}97 \\
100\end{array}$ & $\begin{array}{l}88 \\
\cdots\end{array}$ & $\begin{array}{c}103 \\
\ldots\end{array}$ \\
\hline $\begin{array}{l}\text { Cetrimide } \\
\text { Chlorhexidine } \\
\text { Phenol } \\
\text { Polymyxin }\end{array}$ & $\begin{array}{c}3 \mu \mathrm{g} \\
5 \mu \mathrm{g} \\
3.5 \mathrm{mg} \\
250 \mathrm{u}\end{array}$ & $\begin{array}{r}90 \\
120 \\
90 \\
180\end{array}$ & $\begin{array}{r}26 \\
11 \\
7 \\
15\end{array}$ & $\begin{array}{c}17 \\
43 \\
<2 \times 10^{-4} \\
104\end{array}$ & $\begin{array}{c}17 \\
12 \\
5 \times 10^{-2} \\
\ldots\end{array}$ & $\begin{array}{c}9 \\
72 \\
<2 \times 10^{-4} \\
\ldots\end{array}$ \\
\hline
\end{tabular}

Abbreviations as in table IV.

* Mean of two or three experiments. 
polymyxin than the cultures from which they were derived (table VIII). Sc from strains NCTC nos. 5887 and 7827, NCIB10466, and RBH grew readily when plated on MacConkey agar, indicating that there had been no significant increase in sensitivity to bile salts.

\section{DisCUSSION}

There have been several reports of small-colony variants of gram-negative bacteria, which differ from the parent organisms in intrinsic resistance to antibiotics (Pseudomonas aeruginosa, Annear, 1976; various Enterobacteriaceae, Musher, Baughn and Merrell, 1979) and to disinfectants (Ps. aeruginosa, Brown, M.W., 1977). Some appear to be stable; others revert readily to typical organisms. The Sc variants of Proteus described here appeared to be stable, so the possibility of contamination had to be excluded. They were isolated at intervals during several years by several independent workers, but were not present in cultures of other gram-negative genera studied in the same conditions. A computer identification based on biochemical tests of Sc from three strains confirmed that they were three different organisms, but suggested a resemblance to Pseudomonas picketti. However, comparison with an authentic culture of the latter, the type strain ATCC27511, showed important differences. Ps. picketti was urease negative and phenylalanine-deaminase negative and was never observed to form chains.

Many Sc variants differ biochemically from the parent organisms. Marked differences in synthetic activity have been reported for variants of Escherichia coli (Borderon and Horodniceanu, 1978; Maskell et al., 1978). Some of these differences involve respiratory pathways (Cox and Gibson, 1966; Wulff, 1967). The proteus Sc reported here are no exception. The biochemical differences noted were mainly associated with fermentative and oxidative pathways, and cells were motile only in the presence of added glucose. The changes in haem enzymes in the Sc variants may be associated with their increased resistance to aminoglycosides. Slow-growing mutants of $P$ s. aeruginosa with altered terminal electron transport show a marked decrease in the rate of uptake of aminoglycosides (Bryan and Kwan, 1980) and in $E$. coli streptomycin uptake appears to depend on the functioning of the electron-transport system (Campbell and Kadner, 1980). A similar relationship between aminoglycoside resistance and energy defects in Sc variants has also been noted in staphylococci (Lacey, 1969). It is of interest that an increase in resistance to aminoglycoside and to $\beta$-lactam antibiotics and, in the case of $P$. mirabilis strain $\mathrm{RBH}$, to polymyxin, was associated with increased sensitivity to tetracycline. A similar result was obtained by Brown, Fenton and Watkins (1972) with mutants of Ps. aeruginosa selected for resistance to polymyxin by serial subculture.

Sc variants of Proteus closely resemble the phase-B variants of Belyavin (1951) in cellular and colonial morphology and in sensitivity to $\mathrm{NaCl}$. Cultures containing $0 \cdot 1-0 \cdot 2 \mathrm{M} \mathrm{KCl}$ formed variable numbers of Sc. This is compatible with a random mutation as in a fluctuation test and is presumably determined by the relative effects of salts on growth rate and quantity of 
growth. Belyavin considered that the variation phase $A$ to phase $B$ represented a partial change from smooth to rough. Stability tests in saline, done as described by Belyavin (1951), showed negligible surface changes in $P$. mirabilis strains RBH, and NCTC nos. 5887 and 8309 Sc variants. Their resistance to bile salts, however, as shown by their growth on MacConkey agar, distinguished them from the well characterised deep rough mutants of Salmonella typhimurium described by Ames, Spudich and Nikaido (1974). The changes in sensitivity to antibiotics and disinfectants of Sc variants probably indicate some cell-envelope changes; the latter are known to affect the penetration of various drugs (Brown, Gilbert and Klemperer, 1979).

The most striking feature of these Sc variants is their sensitivity to high salt concentrations, another property that may arise from cell-envelope changes. More importantly, it may lead to confusing results during the isolation of Proteus spp. To prevent swarming, Naylor (1960) advocated the use of media without added $\mathrm{NaCl}$. In such conditions, as on CLED agar, many Sc could grow and not be distinguished from Lc. On the other hand, Kopper (1962) advocated $4 \%($ c. $0.7 \mathrm{M}) \mathrm{NaCl}$, which would suppress the growth of Sc variants. Anderson (1976) points out the problem of diagnostic media differing from the wild habitat, and the use of firm agar (Hayward, Incledon and Spragg, 1978) seems to be the most reliable in this context. The drug resistance of Sc variants suggests that they may be selected in vivo, even if their initial virulence is low. Some, however, may be as virulent as the parent strains. Musher et al. (1979) selected Sc variants of Proteus spp. by exposure to gentamicin and found the LD50 for mice to be the same as that of the parent organisms and that urinary-tract infections could be established experimentally. In preliminary experiments to compare rates of phagocytosis by human polymorphonuclear leucocytes, Sc variants of strains NCTC nos. 5887 and 8309 were ingested at the same rate as their parent organisms, but Sc variants of $\mathrm{RBH}$ were ingested more rapidly.

Proteus is a common hospital contaminant and is one of the genera suggested by Kelsey and Maurer (1974) for the testing of disinfectants. The defined medium they recommend is that of Wright and Mundy (1960), which contains $0.85 \% \mathrm{Na}^{+}$and $\mathrm{K}^{+}$salts and is therefore likely to allow Sc variants to grow. If the medium were to be modified, to permit identification of the limiting nutrient(s) and therefore more strictly defined inocula (Brown, M. R. W., 1977), its osmolarity would certainly have to be taken into account.

We thank Dr Elizabeth Roe, The Accident Hospital, Birmingham, for doing the preliminary tests of phagocytosis, the Public Health Laboratory Service Computer Identification Laboratory for computer identification, and Mrs Dorothy Townley and Mrs Irene Twinn for expert technical assistance with some of the work. D.A.A. was in receipt of a scholarship from Government of Iraq.

\section{REFERENCES}

Al-Dujaili, D. A., Klemperer, R. M. M. and Brown, M. R. W. 1977. The effect of nutrient depletion on the drug resistance of a polymyxin-sensitive Proteus mirabilis. J. Pharm. Pharmac., 29S, suppl., 8P. 
Ames, G. F.-L., Spudich, E. N. And Nikaido, H. 1974. Protein composition of the outer membrane of Salmonella typhimurium: effect of lipopolysaccharide mutations. J. Bact., $117,406$.

ANDERSON, J. D. 1976. The relevance of urine and serum antibacterial activity to the treatment of urinary tract infections. J. antimicrob. Chemother., 2, 226.

ANNEAR, D. I. 1976. Linked and unstable characteristics of colony structure, gentamicin resistance and colistin resistance in Pseudomonas aeruginosa. Microbios Letts, 3, 203.

Belyavin, G. 1951. Cultural and serological phases of Proteus vulgaris. J. gen. Microbiol., 5, 197.

BORDERON, E. AND HORODNiCEANu, T. 1978. Metabolically deficient dwarf-colony mutants of Escherichia coli: deficiency and resistance to antibiotics of strains isolated from urine cultures. J. clin. Microbiol., 8, 629.

Brown, M. R. W. 1977. Nutrient depletion and antibiotic susceptibility. J. antimicrob. Chemother., 3, 198.

Brown, M. R. W., Fenton, E. M. and Watkins, W. M. 1972. Tetracycline-sensitive/polymyxin-resistant Pseudomonas aeruginosa. Lancet, 2, 86.

Brown, M. R. W., GilberT, P. And Klemperer, R. M. M. 1979. Influence of the bacterial cell envelope on combined antibiotic action. In Antibiotic interactions, edited by $\mathrm{J}$. D. Williams, Academic Press, London, p. 69.

BRown, M. W. 1977. The occurrence of variants of Pseudomonas aeruginosa NCTC 6750. J. Pharm. Pharmac., 29, 782.

BRYAN, L. E. AND KWAN, S. L. 1980. Mutants of Pseudomonas aeruginosa with altered susceptibilities to aminoglycosides and abnormalities of terminal electron transport. In Current chemotherapy and infectious disease, edited by J. D. Nelson and C. Grassi, American Society of Microbiology, vol. 1, Washington, DC, p. 704.

CAMPBell, B. D. AND KADNER, R. J. 1980 . Relation of aerobiosis and ionic strength to the uptake of dihydrostreptomycin in Escherichia coli. Biochim. biophys. Acta, 593, 1.

Cowan, S. T. 1974. Cowan and Steel's Manual for the identification of medical bacteria, 2nd ed., Cambridge University Press, Cambridge, p. 112.

Cox, G. B. AND GiBson, F. 1966. The role of shikimic acid in the biosynthesis of vitamin K2. Biochem. J., 100, 1.

Felix, A. 1922. Ueber Varianten der Proteus X-Stämme. Z. Immunität., 35, 57.

HAYWARD, N. J., InCLEDON, G. M. AND SPRAGG, J. E. 1978. Effect of firm agar on the swarming of Proteus and Clostridium species and on the colonies of clinically important bacteria. $J$. med. Microbiol., 11, 155.

Kelsey, J. C. AND MaUrer, I. M. 1974. An improved (1974) Kelsey-Sykes test for disinfectants. Pharm. J., 213, 528.

KoHn, S. R., Gershenfeld, L. AND BARR, M. 1963. Effectiveness of antibacterial agents presently employed in ophthalmic preparations as preservatives against Pseudomonas aeruginosa. J. pharm. Sci., 52, 967.

KOPPER, P. H. 1962. Effect of sodium chloride concentration on the swarming tendency of Proteus. J. Bact., 84, 1119.

LACEY, R. W. 1969. Dwarf-colony variants of Staphylococcus aureus resistant to aminoglucoside antibiotics and to a fatty acid. J. med. Microbiol., 2, 187.

Maskell, R., Okubadejo, O. A., Payne, R. H. and Pead, L. 1978. Human infections with thymine-requiring bacteria. J. med. Microbiol., 11, 33.

Meynell, G. G. And Meynell, E. 1970. Theory and practice in experimental bacteriology, 2nd ed., Cambridge University Press, Cambridge, p. 178.

Musher, D. M., Baughn, R. E. AND Merrell, G. L. 1979. Selection of small-colony variants of Enterobacteriaceae by in vitro exposure to aminoglycosides: pathogenicity for experimental animals. J. inf. Dis., 140, 209.

NAYLOR, P. G. D. 1960. A simple medium which controls the swarming of Proteus. J. med. Lab. Technol., 17, 182.

Russell, A. D., Ahonkhai, I. And Rogers, D. T. 1979. Microbiological applications of the inactivation of antibiotics and other antimicrobial agents. J. appl. Bact., 46, 207. 
SNell, J. J. S. AND DaveY, P. 1971. A comparison of methods for the detection of phenylalanine deamination by Moraxella species. J. gen. Microbiol., 66, 371.

WRIGHT, E. S. AND Mundy, R. A. 1960. Defined medium for phenol coefficient tests with Salmonella typhosa and Staphylococcus aureus. J. Bact., 80, 279.

WuLFF, D. L. 1967. $\delta$-aminolevulinic acid-requiring mutant from Escherichia coli. J. Bact.,93, 1473. 